\title{
Peran Dukungan dan Hambatan Kontekstual Terhadap Adaptabilitas Karier pada Mahasiswa Tingkat Akhir
}

\author{
Karinda Ayu Tamari \\ Sari Zakiah Akmal
}

Program Studi Psikologi, Fakultas Psikologi Universitas YARSI, Jakarta

\begin{abstract}
A senior college student is an individual who is in a transition from college to work life. In this transition period, last-year college students need to prepare themselves to face difference role as a worker. Furthermore, the phenomenon of college students who do not always work in accordance to their majors getting more. Therefore, having high career adaptability is important skill for students. One of the important factor that can influence an individual's career choice is an external factor or can be called as a form contextual support and barrier. This research was conducted to find out the role of contextual support and barrier to career adaptability at final grade student in Jabodetabek. The study used a Career Adapt-Abilities Scale (CAAS) and Contextual Support and Barriers Scale (CSB). The subjects of this study were 270 college students in Jabodetabek, which obtained from quota sampling technique in each region is represented by 30 sample. The role of contextual support and barrier to career adaptability tested by simple regression. The results showed that contextual support participated for $14.5 \%$ of career adaptability $(\mathrm{p}<0.05)$. Meanwhile, contextual barriers felt by final-year college student are insignificant to career adaptability. Therefore, giving support to final-year college students is an intervention that can be given to improve their career adaptability.
\end{abstract}

Keywords: career adaptability, contextual support and barrier, senior college students.

\begin{abstract}
Abstrak. Kehidupan mahasiswa tingkat akhir berada pada transisi dari dunia kuliah menuju dunia kerja. Untuk menghadapi perbedaan antara dunia kuliah dan dunia kerja, mahasiswa perlu mempersiapkan diri. Selain itu, semakin banyak ditemukan fenomena bahwa mahasiswa tidak selalu dapat bekerja yang sesuai dengan jurusannya. Oleh karena itu, mahasiswa dituntut memiliki adaptabilitas karier yang tinggi. Salah satu faktor penting yang dapat mempengaruhi pilihan karier individu adalah faktor eksternal yang disebut sebagai dukungan dan hambatan kontekstual. Tujuan dari penelitian ini adalah untuk mengetahui bagaimana peran dukungan dan hambatan kontekstual terhadap adaptabilitas karier pada mahasiswa tingkat akhir di Jabodetabek. Penelitian ini menggunakan alat ukur Career Adapt-Abilities Scale (CAAS) dan Contextual Support and Barrier (CSB). Penelitian ini melibatkan responden sebanyak 270 orang mahasiswa yang aktif berkuliah di Jabodetabek. Rekrutmen responden menggunakan teknik quota sampling yang di setiap wilayah diwakili oleh 30 orang sampel. Dengan melakukan analisis regresi sederhana, hasilnya menunjukan bahwa dukungan kontekstual berperan sebesar 14,5\% terhadap adaptabilitas karier $(\mathrm{p}<0,05)$. Sedangkan, hambatan kontekstual yang dirasakan oleh mahasiswa tingkat akhir tidak berperan secara signifikan terhadap adaptabilitas karier. Oleh karena itu, pemberian dukungan terhadap mahasiswa tingkat akhir merupakan intervensi yang dapat diberikan untuk meningkatkan adaptabilitas karier mereka.
\end{abstract}

Kata kunci: adaptabilitas karier, dukungan dan hambatan kontekstual, mahasiswa tingkat akhir

Korespondensi: Karinda Ayu Utami. E-mail: karin.tamari@gmail.com. 
Mahasiswa tingkat akhir berada pada tahap perkembangan dewasa awal. Menurut Santrock (2002) tugas perkembangan masa dewasa awal adalah hidup berkeluarga, mulai bekerja dalam suatu jabatan, dan memperoleh kelompok sosial yang seirama. Dengan kata lain, masa dewasa awal adalah masa dimana mahasiswa mestinya sudah mulai bekerja atau memikirkan karier di masa depannya. Sebagai individu yang akan bekerja, mahasiswa perlu mempunyai kompetensi dasar seperti kemampuan komunikasi yang efektif terhadap atasan, kemampuan komunikasi bawahan dan sesama pekerja, kemampuan memimpin yang baik, kemampuan berinisiatif yang tinggi, kemampuan menjadi tim kerja yang baik, fleksibel, dan kemampuan beradaptasi dengan lingkungan sekitar. Kemampuan tersebut mencerminkan kemampuan adaptabilitas (Fitriani, 2018).

$$
\text { Pada kenyataannya, sebagian }
$$

mahasiswa belum memiliki kompetensi adaptabilitas. Hal ini sejalan dengan pendapat Putra (2013) bahwa lulusan baru cenderung tidak siap untuk langsung bekerja. Selain itu, masalah lain yang seringkali muncul pada lulusan baru pada generasi milenial ini adalah mereka cenderung berpindah-pindah pekerjaan (kutu loncat). Fenomena ini muncul karena generasi milenial cenderung menginginkan sesuatu secara instan, seperti ingin memiliki pekerjaan yang jabatannya tinggi (Fitriani, 2018). Menurut Ng, Hirono, dan Siy (1986), seseorang yang terlalu cepat keluar dari tempat kerja atau kutu loncat dianggap merugikan, sebab perusahaan khawatir mereka akan menyebarkan rahasia perusahaan kepada perusahaan kompetitor.

Selain munculnya fenomena kutu loncat, terdapat pula lulusan baru yang bekerja tidak sesuai dengan jurusannya. Menurut laporan menteri ketenagakerjaan, pertumbuhan angkatan kerja baru rata-rata sekitar dua juta orang per tahunnya. Dari dua juta orang tersebut, ada sebanyak 63\% yang bekerja tidak sesuai dengan jurusannya (Mardiana, 2017). Berdasarkan dari dua fenomena ini maka mahasiswa perlu dibekali dengan kemampuan untuk menyesuaikan diri di lingkungan kerja agar dapat menunjukkan performa yang baik dan bertahan di dunia kerja.

Mahasiswa perlu lebih mempersiapkan diri untuk memasuki dunia kerja karena mahasiswa sedang berada pada masa transisi sekolah ke pekerjaan (Koen, Klehe, \& Vianen, 2012). Masa transisi sekolah ke pekerjaan ini merupakan pengalaman yang akan dirasakan oleh para mahasiswa yang akan masuk ke dunia kerja. Kemudian, informasi mengenai dunia kerja juga penting bagi mahasiswa agar dapat cepat untuk menyesuaikan diri ke dunia kerja (Sziraczki \& Reerink, 2004). Data survei tahun 2003 dari ILO dan Departemen Tenaga Kerja dan Transmigrasi (Depnakertrans) menggunakan sampel sebanyak 2.180 remaja dan mahasiswa ditambah 90 pekerja dari 
berbagai perusahaan, diketahui bahwa mahasiswa cenderung tidak memiliki pengetahuan yang cukup tentang kesempatan-kesempatan yang ada di pasar kerja sehingga mereka kurang bisa mempersiapkan diri memasuki dunia kerja.

Dalam masa transisi, mahasiswa tingkat akhir akan mengalami kesulitan dalam mendapat pekerjaan yang sesuai dengan bidangnya saat memasuki dunia kerja (Koen, Klehe, \& Vianen, 2012). Untuk mengatasi kesulitan dalam menemukan pekerjaan, mahasiswa perlu mengetahui perbedaan antara dunia kuliah dan dunia kerja. Menurut Sherly (2017), perbedaan yang terlihat pada dunia kuliah dan dunia kerja di antaranya, mahasiswa dapat meminta bantuan rekan atau dosen ketika mengalami kesulitan, sedangkan pekerja dituntut untuk mampu menyelesaikan tugasnya secara mandiri. Mahasiswa tidak memiliki tugas rutin, sedangkan pekerja mempunyai tugas rutin setiap harinya. Pemahaman tentang perbedaan antara dunia kuliah dan dunia kerja tersebut mahasiswa diharapkan dapat menyiapkan diri mereka pada dunia kerja.

Menurut Wurianda (2016), kemampuan beradaptasi adalah penting bagi lulusan baru dalam mempersiapkan diri ke dunia kerja yang banyak melakukan komunikasi dengan atasan, teman sejawat, atau bawahan. Menurut Wang dan $\mathrm{Fu}$ (2015), memiliki kemampuan beradaptasi pada dunia kerja juga penting bagi mahasiswa yang sedang berada di masa transisi sekolah ke pekerjaan. Kemampuan beradapatasi yang baik akan dapat meningkatkan kesempatan untuk menemukan pekerjaan yang sesuai, sehingga akan meningkatkan kesuksesan dan kesejahteraan karier (Hartung \& Taber, 2008).

Kemampuan beradaptasi pada dunia kerja ini disebut juga sebagai adaptabilitas karier. Savickas dan Porfeli (2012) melihat bahwa adaptabilitas karier merupakan kesiapan individu untuk mengatasi tugastugas, masa transisi pekerjaan, dan trauma dalam peran pekerjaan mereka. Teori tersebut menjelaskan bahwa adaptabilitas karier adalah kemampuan menghadapi tugas yang terduga maupun tidak terduga dari pekerjaan tersebut. Savickas dan Porfeli (2012) merumuskan adaptabilitas karier ke dalam empat dimensi yaitu career concern, career control, career curiosity, dan career confidence. Individu yang memiliki adaptabilitas karier yang baik apabila ia mampu melihat dan mempersiapkan diri untuk menghadapi masa depan (career concern). Selain itu, ia juga mampu mengendalikan masa depan mereka yaitu dengan bertanggung jawab dalam membuat keputusan karier (career control). Selanjutnya, ia juga mampu mengeksplorasi diri sendiri dengan lingkungan kerjanya (career curiosity). Akhirnya, ia juga percaya diri (career confidence) dalam memecahkan masalah yang mereka hadapi untuk mengejar kesuksesan karier mereka 
(Savickas \& Porfeli, 2012; Koen, Klehe, \& Vianen, 2012).

Adaptabilitas karier ini merupakan bagian dari proses perkembangan karier seseorang (Savickas, 1997). Menurut Lent, Brown, \& Hackett (2000), Social Cognitive Career Theory (SCCT) adalah teori yang dapat menjelaskan proses perkembangan karier seseorang. Teori SCCT dalam menjelaskan tentang pemilihan karier serta proses-proses yang terkait dengan karier seseorang, termasuk kemampuan beradaptasi, hal itu dipengaruhi oleh faktor internal dan eksternal. Faktor internal yang dapat mempengaruhi karier seseorang di antaranya efikasi diri, penilaian terhadap hasil yang diharapkan, dan orientasi masa depan. Di sisi lain, faktor eksternal yang dapat mempengaruhi karier seseorang di antaranya faktor kontekstual yang diartikan sebagai keyakinan individu mengenai adanya faktor orang lain dan lingkungan yang dapat meningkatkan kemampuan dirinya sendiri (Lent, Brown, \& Hackett, 1994).

Penelitian ini berfokus pada peran faktor eksternal karena individu dengan budaya kolektivis perlu memiliki dukungan psikologis yang kuat dari orang lain agar mampu beradaptasi dalam berkarier (Gorodnichenko \& Roland, 2010). Faktor eksternal yang didapatkan oleh individu disebut juga sebagai faktor kontekstual, yang terdiri atas dukungan dan hambatan kontekstual. Lent, Brown, dan Hackett
(2000) menjelaskan bahwa dukungan kontekstual akan memfasilitasi atau membantu individu dalam mengatasi masalah di lingkungan kerja. Sedangkan hambatan kontekstual hambatan yang sering dialami oleh individu dalam pencapaian kariernya. Menurut Lent, Brown, \& Hackett (2000), aspek dalam dukungan dan hambatan kontekstual antara lain adalah gender, etnis, status ekonomi, institusi pendidikan, dan lingkungan sosial. Lent, dkk. (2002) juga mengatakan bahwa teman, anggota keluarga adalah faktor pendukung yang penting lainnya.

Beberapa hasil penelitian di negara lain mengungkapkan bahwa dukungan kontekstual dapat meningkatkan adaptabilitas karier. Hasil penelitian Guan, dkk. (2013) menunjukkan bahwa dukungan orangtua dapat meningkatkan adaptabilitas karier pada mahasiswa di China. Interaksi antar anggota keluarga yang baik dan apresiasi dari perusahaan dapat meningkatkan adaptabilitas karier seseorang yang sedang di tahap masa transisi sekolahpekerjaan (Ebberwein, Krieshok, Prosser, \& Ulven, 2004). Sedangkan dari hasil penelitian pada remaja di Swiss yang dilakukan oleh Hirschi (2009), dapat diketahui bahwa dukungan kontekstual merupakan prediktor yang kuat untuk meningkatkan adaptabilitas karier dibandingkan dengan prediktor yang lain misalnya disposisi emosi, penentuan tujuan 
masa depan, atau kemampuan keyakinan diri.

Beberapa hasil penelitian mengungkapkan bahwa hambatan kontekstual dapat menurunkan adaptabilitas karier seseorang. Hasil penelitian Lent, dkk. (2002) menggambarkan bahwa hambatan kontekstual dapat mempengaruhi tindakan terkait karier seseorang. Sejalan dengan penelitian tersebut, hasil penelitian Soresi, Nota, dan Ferrari (2012) menunjukkan bahwa antara adaptabilitas karier dan hambatan yang dirasakan oleh remaja di Italia berkorelasi negatif. Semakin tinggi adaptabilitas karier individu maka semakin rendah hambatan yang dirasakan individu.

Selain itu, perbedaan peran budaya yang dimiliki individu juga mampu mempengaruhi kemampuan beradaptasi seseorang (Savickas \& Porfeli, 2012). Peran budaya tersebut dapat diartikan bahwa setiap individu akan berbeda-beda dalam menanggapi hal terkait adaptabilitas karier tergantung dengan budaya apa yang dianut, pemikiran, perilaku dan sifat orang tertentu. Seperti dalam penelitian Omar dan Noordin (2014) mengungkapkan bahwa ada perbedaan adaptabilitas karier pada karyawan di Malaysia antara seseorang yang memiliki budaya individualis dan budaya kolektivis. Menurut Omar dan Noordin (2014) pengambilan keputusan karier seorang yang menganut budaya kolektivis didasarkan pada persepsi orang lain dalam kelompoknya, berbeda dengan seorang yang menganut budaya indivi-dualis, keputusannya didasarkan oleh pilihan internal dan kurang bergantung pada sosial. Cara kerja seseorang cenderung berubahberubah sehingga diperlukan individu yang fleksibel dan mampu beradaptasi dengan karier untuk dapat sukses dalam kariernya (Gallivan, 2004). Budaya kolektivis dan budaya individual itu berbeda dalam hal beradaptasi dalam dunia kerja. Penelitian sebelumnya cenderung dilakukan di negara dengan budaya individualis, sementara itu penelitian di negara kolektivis baru dilakukan di Malaysia.

Di Indonesia, penelitian mengenai dukungan sosial dengan adaptabilitas karier sudah dilakukan namun penelitian terdahulu umumnya menggunakan populasi remaja. Salah satu contohnya yaitu penelitian Angelika dan Gunawan (2016) yang mengungkapkan bahwa dukungan sosial mampu meningkatkan adaptabilitas karier pada remaja di Grogol, Jakarta Barat. Selanjutnya, penelitian lain oleh Zulfiani (2017) menemukan bahwa dukungan orangtua dapat meningkatkan adaptabilitas karier pada remaja, di mana semakin tinggi dukungan diberikan oleh orangtua maka semakin tinggi juga adaptabilitas karier mereka. Dukungan keluarga, dukungan orangtua, dan dukungan sosial ini merupakan aspek-aspek yang mewakili dukungan kontekstual.

Selain itu, hambatan kontekstual diduga juga turut berperan terhadap 
adaptabilitas karier, sehingga aspek ini perlu diikutsertakan dalam penelitian ini. Penelitian hambatan kontekstual masih jarang dilakukan di Indonesia, sehingga penelitian mengenai hambatan kontekstual juga perlu dilakukan. Mahasiswa memiliki karakteristik yang berbeda dengan remaja, mahasiswa dianggap dapat lebih proaktif terhadap perubahan karier dan dapat mencakup penilaian yang realistis terhadap karier dan pribadi orang lain (Ebberwein, dkk., 2004). Hal inilah yang membuat penelitian mengenai dukungan dan hambatan kontekstual perlu juga dilakukan pada sampel mahasiswa. Berdasarkan uraian sebelumnya maka peneliti ingin melihat bagaimana peranan dukungan dan hambatan kontekstual terhadap adaptabilitas karier pada mahasiswa tingkat akhir di Jabodetabek. Pemilihan lokasi Jabodetabek ini dilatarbelakangi oleh data dari Badan Pusat Statistik (BPS) pada tahun 2017, bahwa wilayah Jakarta dan sekitarnya memiliki peringkat mahasiswa terbanyak di Indonesia.

\section{Metode}

Hipotesis dalam penelitian ini adalah ada korelasi antara peranan dukungan dan hambatan kontekstual terhadap adaptabilitas karier pada mahasiswa tingkat akhir di Jabodetabek. Untuk menguji hipotesis ini maka penelitian ini menggunakan pendekatan kuantitatif dengan desain penelitian asosiatif.

\section{Responden penelitian}

Penelitian ini bertujuan untuk melihat peranan variabel dukungan dan hambatan kontekstual terhadap adaptabilitas karier pada 270 orang mahasiswa aktif tingkat akhir yang tersebar di wilayah Jadebotabek. Sampel diperoleh dengan teknik quota sampling, setiap wilayah Jakarta (5 wilayah), Depok, Bogor, Tangerang dan Bekasi diwakili oleh 30 sampel.

\section{Pengumpulan data}

Data dalam penelitian ini dikumpulkan dengan menggunakan kuesioner yang terdiri atas data demografis (jenis kelamin, usia, lokasi universitas, semester, jurusan dan alasan memilih jurusan), Career AdaptAbilities Scale (untuk mengukur adaptabilitas karier) dan Contextual Support and Barrier Scale (untuk mengukur hambatan dan dukungan kontekstual).

Alat ukur adaptabilitas karier merupakan adaptasi dari Career AdaptAbilities Scale (CAAS) yang dikembangkan oleh Savickas dan Porfeli (2012) yang bertujuan untuk melihat seberapa kuat individu dalam mengembangkan masingmasing kemampuan terkait karier. Alat ukur itu terdiri dari 24 aitem, dengan lima alternatif jawaban; Sangat Tidak Kuat (1), Tidak Kuat (2), Kuat (3), Agak Kuat (4), dan Sangat Kuat (5). Hasil uji coba alat ukur menggunakan 50 sampel menunjukkan bahwa seluruh aitem pada alat ukur tersebut 
merupakan alat ukur yang valid dan memiliki koefisien reliablitas 0,946.

Sementara itu, alat ukur dukungan dan hambatan kontekstual dilakukan dengan berdasarkan alat ukur Social Cognitive Career Theory (SCCT) yang dibuat oleh Lent, dkk. (2002). Alat ukur ini terdiri dari 38 aitem dengan 15 aitem dimensi dukungan kontekstual dan 23 aitem dimensi hambatan kontekstual, dengan empat alternatif jawaban; Sangat Tidak Setuju (STS), Tidak Sesuai (TS), Sesuai (S), Sangat Sesuai (SS). Berdasarkan hasil perhitungan reliabilitas pada uji coba alat ukur dukungan dan hambatan kontekstual, didapatkan koefisien reliabilitas pada dimensi dukungan yaitu 0,821, sedangkan pada dimensi hambatan didapatkan koefisien reliabilitas 0,920 .

\section{Teknik analisis data}

Pengujian hipotesis menggunakan teknik statistik regresi. Sebelum melakukan uji regresi, dilakukan uji normalitas dan uji linieritas data. Berdasarkan hasil dari uji normalitas yang telah dilakukan, diketahui bahwa data penelitian ini berdistribusi normal (KS-Z = 0,653 dan $\mathrm{p}>0,05)$. Hasil uji linieritas menunjukkan dimensi dukungan kontekstual memiliki hubungan yang linier dengan variabel adaptablitas karier $(\mathrm{F}=$ $47,214, p=0,000)$. Sedangkan, dapat terlihat bahwa dimensi hambatan kontekstual tidak memiliki hubungan yang linier dengan variabel adaptabilitas karier $(\mathrm{F}=1,985, \mathrm{p}=$ 0,160). Oleh karena itu, uji regresi hanya dilakukan untuk mengetahui peranan dukungan kontekstual terhadap adaptabilitas karier.

\section{Hasil}

\section{Data demografis responden penelitian}

Responden penelitian ini berjumlah 270 orang yang merupakan mahasiswa aktif tingkat akhir yang berkuliah di Jabodetabek dengan rentang usia 20-24 tahun $(M=21,26$, $\mathrm{SD}=0,782$ ). Mayoritas responden penelitian berjenis kelamin perempuan (64,4\%). Mayoritas responden memilih sendiri untuk berkuliah di jurusan yang diambil sebanyak $84,07 \%$, sebanyak $70,37 \%$ responden berstatus mahasiswa semester 8 .

\section{Hasil uji hipotesis penelitian}

Hasil uji regresi peranan dukungan kontekstual terhadap adaptabilitas karier dapat dilihat pada tabel berikut ini

Tabel 1. Hasil Uji Regresi

\begin{tabular}{cccc}
\hline $\mathbf{F}$ & $\mathbf{p}$ & $\mathbf{R}^{2}$ & $\boldsymbol{\beta}$ \\
\hline 45,625 & 0,000 & 0,145 & 64,509 \\
& & &, 685 \\
\hline
\end{tabular}


Tabel $1 \mathrm{di}$ atas menunjukkan bahwa dukungan kontekstual berperan terhadap adaptabilitas karier pada mahasiswa tingkat akhir di Jabodetabek. Hasil analisa regresi sederhana didapatkan $\mathrm{R}^{2}$ sebesar 0,145. Hal tersebut dapat menunjukan variabel dukungan kontekstual sebesar 14,5\% berperan terhadap adaptabilitas karier $\left(\mathrm{R}^{2}=\right.$ 0,145, $F(1,269)=45,625, p<0,01)$. Selain itu, ditemukan bahwa dukungan kontekstual memiliki koefisien regresi yang signifikan dalam memprediksi adaptabiltas karier $(\beta$ $=0,685, \mathrm{p}<0,01)$. Persamaan regresi antara dukungan kontekstual dengan adaptabilitas karier ditunjukkan dengan persamaan sebagai berikut $(Y=64,509+$ $0,685 X)$.

\section{Pembahasan}

Hasil penelitian ini menunjukkan bahwa dukungan kontekstual berperan secara signifikan terhadap adaptabilitas karier mahasiswa tingkat akhir. Hal tersebut menunjukkan bahwa ketika mahasiswa merasakan dukungan kontekstual yang tinggi, maka adaptabilitas karier yang dirasakan akan meningkat. Besarnya peranan dukungan kontekstual terhadap adaptabilitas karier mahasiswa tingkat akhir sebesar 14,5\%. Hasil penelitian ini sejalan dengan penelitian Hirschi (2009) yang menyatakan bahwa prediktor yang kuat untuk meningkatkan adaptabilitas karier yaitu dukungan kontekstual. Lalu, penelitian Angelika dan Gunawan (2016) menyatakan bahwa dukungan sosial mampu meningkatkan adaptabilitas karier. Selain itu, penelitian Guan, dkk. (2013) juga menyatakan bahwa dukungan dari orangtua dapat meningkatkan adaptabilitas karier. Ketika individu mendapatkan dukungan yang besar dari lingkungan, maka akan membantu individu tersebut menurunkan kekhawatirannya dan dapat meningkatkan persiapan karier yang akan dialaminya di dunia kerja (Han \& Rojewski, 2015).

Menurut Gamboa, Paixao, dan Jesus, (2014) faktor kontekstual dapat mengembangkan eksplorasi karier individu. Dukungan dapat membantu mahasiswa tingkat akhir tersebut mendapatkan pemahaman terkait karier agar dapat mengendalikan masa depan karier mereka serta dapat menambah informasi dan pemahamannya terkait karier yang akan dijalani. Dengan adanya dukungan kontekstual yang dirasakan oleh mahasiswa tingkat akhir dapat membantu individu tersebut untuk belajar memecahkan masalah terkait karier yang akan mereka hadapi.

Sementara itu, penelitian ini menemukan bahwa hambatan kontekstual tidak memiliki peranan yang signifikan terhadap adaptabilitas karier atau dapat dikatakan hipotesis alternatif pada hambatan kontekstual ditolak. Hal tersebut menunjukkan bahwa ketika mahasiswa merasakan tingkat hambatan kontekstual yang tinggi, maka tidak akan berdampak 
secara signifikan terhadap adaptabilitas karier yang dimiliki oleh mahasiswa tersebut.

Hasil penelitian ini berbeda dengan penelitian sebelumnya yang mengungkapkan bahwa adanya hambatan yang dirasakan oleh individu dapat menurunkan adaptabilitas karier yang dirasakan oleh individu (Soresi, Nota, \& Ferrari, 2012). Selanjutnya secara teoretis hambatan dari lingkungan dapat menjadi penghalang untuk meningkatkan persiapan karier yang akan dialami individu pada pekerjaannya di masa depan. Menurut Lent, dkk. (2002) hambatan yang diterima individu dalam proses kesiapan karier juga dapat menjadi penghalang untuk individu mencari informasi, menambah informasi dan pemahaman terkait karier yang akan dijalaninya serta individu dapat memecahkan masalah dan mengatasi rintangan-rintangan dalam dunia kerja. Hambatan yang diperoleh individu juga dapat menjadi penghalang untuk individu tersebut dalam mendapatkan pemahaman mengenai karier untuk mengendalikan masa depan individu tersebut dengan baik (Soresi, Nota, \& Ferrari, 2012).

Penelitian ini memiliki kelebihan dan kekurangan yang dapat menjadi pertimbangan untuk penelitian selanjutnya. Kelebihan dari penelitian ini adalah peneliti dapat menggambarkan besaran peranan antara faktor eksternal berdasarkan dukungan dan hambatan kontekstual terhadap adaptabilitas karier yang dirasakan mahasiswa tingkat akhir. Dengan demikian, peneliti dapat mengetahui, di antara dimensi dukungan dan hambatan kontekstual, dimensi mana yang paling signifikan berperan terhadap adaptabilitas karier seseorang.

Sedangkan kekurangan dalam penelitian ini adalah masih ditemukan ada 85,5\% faktor lain yang mempengaruhi adaptabilitas karier seseorang selain variabel yang diteliti pada penelitian ini. Berdasarkan teori SCCT, faktor yang dapat mempengaruhi pilihan karier serta proses-proses terkait karier yaitu faktor internal dan eksternal. Penelitian ini hanya meneliti faktor eksternal dari teori SCCT yaitu dukungan dan hambatan kontekstual. Masih ada sejumlah faktor internal penting yang belum diteliti dengan adaptabilitas karier yaitu efikasi diri, penilaian terhadap hasil yang diharapkan, dan orientasi masa depan. Selain itu, penelitian ini hanya meneliti di daerah Jabodetabek sehingga tidak dapat mereprentasikan budaya di Indonesia yaitu budaya kolektif maka sebaiknya dilakukan penelitian dengan populasi yang lebih luas mewakili seluruh provinsi di Indonesia. 


\section{Simpulan}

Hasil dari penelitian ini menunjukan bahwa dukungan kontekstual yang dirasakan oleh responden berperan secara signifikan terhadap adaptabilitas karier mahasiswa tingkat akhir. Sedangkan, hambatan kontekstual yang dirasakan oleh responden tidak signifikan berperan terhadap adaptabilitas karier mahasiswa tingkat akhir.

\section{Saran}

Saran yang dapat diberikan berdasarkan proses penelitian dan hasil penelitian ini, adalah:

\section{Saran Teoritis}

Pertama, untuk penelitian selanjutnya, disarankan untuk melakukan pengembangan penelitian dengan melihat peranan faktor eksternal dan internal dari dalam diri individu seperti gender, status ekonomi, penilaian terhadap hasil yang diharapkan, dan orientasi masa depan. Kemudian untuk penelitian selanjutnya diharapkan untuk melibatkan populasi yang lebih besar dengan sampel yang mewakili setiap daerah-daerah di Indonesia agar hasil dapat tergeneralisasikan dengan baik.

\section{Saran Praktis}

Berdasarkan hasil penelitian ini, diketahui bahwa dukungan kontekstual memiliki peranan yang signifikan terhadap adaptabilitas karier yang dirasakan oleh seseorang. Dengan demikian, saran yang dapat diberikan untuk meningkatkan adaptabilitas karier adalah meningkatkan dukungan dari luar diri mahasiswa dalam mempersiapkan diri ke dunia kerja. Pertama untuk orangtua dan teman sebaya, sebaiknya lebih memberi informasi dan arahan terkait dunia pekerjaan kepada anak/rekan, agar mereka lebih bisa mempersiapkan diri untuk memasuki dunia kerja. Kemudian untuk institusi perguruan tinggi, sebaiknya dapat memberikan informasi mengenai kesiapan dalam menghadapi karier untuk mahasiswa yang ingin mengikuti program magang dan dapat menjadi acuan untuk dosen pembimbing akademik memberikan konseling karier terhadap mahasiswanya.

\section{Ucapan Terimakasih:}

Penelitian ini merupakan bagian dari penelitian payung dengan judul "Faktoryang Memprediksi Adaptabilitas Karier pada Mahasiswa Tingkat Akhir" yang didanai oleh Hibah Penelitian Internal Universitas YARSI 2018/2019. 


\section{Daftar Pustaka}

Angelika, S., \& Gunawan, W. (2016). Hubungan antara dukungan sosial dengan adaptabilitas karier remaja di kecamatan Grogol Petamburan. Mind Set, 7, 8-16.

Ebberwein, C. A., Krieshok, T., Ulven, J. C., \& Prosser, E. C. (2004). Voices in transition: Lessons on career adaptability. The Career Development Equarterly, 52, 292- 308.

Fitriani, V. R. (2018, April). Work life introduction. Makalah dipresentasikan pada seminar pengembangan soft skill mahasiswa be ready for your brighter future, Universitas YARSI, Jakarta.

Gallivan, M. (2004). Examining IT profesionals' adaptation to technological change: The influence of gender and personal attributes. The DATA BASE for Advances in Information Systems, 35(3), 28-49.

Gamboa, V., Paixao, M. P., \& de Jesus, S.N. (2014). Vocational profiles and internship quality among Portuguese VET students. International Journal for Educational and Vocational Guidance, 14, $1-24$.

Guan, Y., Deng, H., Sun, J., Wang, Y., Cai, Z., Ye, L., Fu, R., Wang, Y., Zhang, S., Li, Y. (2013). Career adaptability, job search selfefficacy and outcomes: A three-wave investigation among Chinese university. Journal of Vocational Behavior, 83, 561570.

Gorodnichenko, Y., \& Roland G. (2011). Understanding the individualismcollectivism cleavage and its effects: Lesson from cultural psychology. Dipresentasikan pada Kongres Asosiasi Ekonomi Internasional XVI, Beijing, China.
Han, H., \& Rojewski, J. W. (2015). Genderspecific models of work- bound Korean adolescents' social supports and career adaptability on subsequent job satisfaction. Journal of Career Development, 42, 149-164.

Hartung, P. J., \& Taber, B. J. (2008). Career construction and subjective well-being. Journal of Career Assessment, 16(1), 7585.

Hirschi, A. (2009). Career adaptability development in adolescence: Multiple predictors and effect on sense of power and life satisfaction. Journal of Vocational Behavior, 74, 145-155.

Koen, J., Klehe, U. C., \& Vianen, A. E. (2012). Training career adaptability to facilitate a successful school-to- work transition. Journal of Vocational Behavior, 81, 395408.

Lent, R. W., Brown, S. D., \& Hackett, G. (1994). Toward a unifying social cognitive theory of career and academic interest, choice, and performance. Journal of Vocational Behavior, 45, 79-122.

Lent, R. W., Brown, S. D., \& Hackett, G. (2000). Contextual supports and barriers to career choice: A social cognitive analysis. Journal of Counseling Psychology, 47, 3649.

Lent, R. W., Brown, S. D., Talleyrand, R., McPartland, E. B., \& Alexander, M.S. (2002). Career choice barriers, supports, and coping strategies: College students' experiences. Journal of Vocational Behavior, 60, 61-72.

Mardiana, C, F. (2017, 29 Agustus). 63\% orang Indonesia bekerja tak sesuai jurusan. Detik Finance. Diunduh dari https://finance.detik.com/beritaekonomi-bisnis/d-3620313/63- orangindonesia-bekerja-tak-sesuai- jurusan. 
Ng, C.Y., Hirono, R., \& Siy, R.Y. (1986). Effective mechanism for the enhancement of technology and skills in ASEAN: An overview. Singapore: Institute of Southeast Asian.

Omar, S., \& Noordin, F. (2014). The influence of individualism-collectivism culture on career adaptability among ICT professionals in Malaysia. Australian Journal of Basic and Applied Sciences, 8, 175-183.

Putra, Y. M. (2013, 28 Mei). Psikolog: Tidak semua 'fresh graduate' siap bekerja. Republika. Diunduh pada dari https://www.republika.co.id/berita/ pendidikan/dunia-kampus/13/05/28/ mngvw5-psikolog-tidak-semua-freshgraduate-siap-bekerja

Santrock, J.W. (2002). Life span development (Penerjemah: Chusairi dan Damanik). Jakarta: Erlangga.

Savickas, M. L. (1997). Career adaptability: An integrative construct for life-span, life-space theory. The Career Development Quarterly, 45, 247-259.

Savickas, M. L., \& Porfeli, E. J. (2012). Career adapt-abilities scale: Construction, reliability, and measurement equivalence across 13 countries. Journal of Vocational Behavior, 80, 661-673.
Sherly. (2017). 9 perbedaan kuliah dan kerja yang kamu perlu ketahui. Idn Times. Diunduh dari https://life.idntimes.com/ career/sherly-8/9-perbedaan-kuliahdan-kerja-yang-kamu-perlu-ketahuic1c2

Soresi, S., Nota, L., \& Ferrari, L. (2012). Career adapt-abilities scale-italian form: Psychometric properties and relationships to breadth of interests, quality of life, and perceived barriers. Journal of Vocational Behavior, 80, 705711.

Sziraczki, G., \& Reerink, A. (2004). Transisi dari sekolah-menuju-dunia kerja di Indonesia. Jakarta, Indonesia: ILO (Organisasi Perburuhan Indonesia).

Wang, Z., \& Fu, Y. (2015). Social support, social comparison, and career adaptability: A moderated mediation model. Social Behavior and Personality. 43, 649-660.

Zulfiani, H. (2017). Adaptabilitas karir ditinjau dari dukungan keluarga, jenis kelamin, dan jenis sekolah (Skripsi). Fakultas lmu Sosial dan Humaiora, Universitas Islam Negeri Sunan Kalijaga, Yogyakarta. 